\title{
Workforce Development and Multiagency Collaborations: A Presentation of Two Case Studies in Child Welfare
}

\author{
Chad McDonald ${ }^{1}\left(\mathbb{D}\right.$, Kristine A. Campbell ${ }^{2}$, Cole Benson ${ }^{1}$, Matthew J. Davis ${ }^{3}$ and Caren J. Frost ${ }^{4, *}(\mathbb{D}$ \\ 1 Social Research Institute, College of Social Work, University of Utah, Salt Lake City, UT 84112, USA; \\ chad.mcdonald@utah.edu (C.M.); cole.benson@utah.edu (C.B.) \\ 2 Department of Pediatrics, School of Medicine, University of Utah, Salt Lake City, UT 84112, USA; \\ kristine.campbell@hsc.utah.edu \\ 3 Population Health Sciences, Health Systems Innovation and Research Division, University of Utah, \\ Salt Lake City, UT 84112, USA; matt.davis@hsc.utah.edu \\ 4 College of Social Work, University of Utah, Salt Lake City, UT 84112, USA \\ * Correspondence: caren.frost@socwk.utah.edu
}

check for

updates

Citation: McDonald, C.;

Campbell, K.A.; Benson, C.;

Davis, M.J.; Frost, C.J. Workforce

Development and Multiagency

Collaborations: A Presentation of Two Case Studies in Child Welfare. Sustainability 2021, 13, 10190. https:// doi.org/10.3390/su131810190

Academic Editors: Juha Hämäläinen, Riitta Vornanen and Kaisa Pihlainen

Received: 5 July 2021

Accepted: 4 September 2021

Published: 13 September 2021

Publisher's Note: MDPI stays neutral with regard to jurisdictional claims in published maps and institutional affiliations.

Copyright: (c) 2021 by the authors. Licensee MDPI, Basel, Switzerland. This article is an open access article distributed under the terms and conditions of the Creative Commons Attribution (CC BY) license (https:// creativecommons.org/licenses/by/ $4.0 /)$.

\begin{abstract}
Background: Two disciplines that work in the child welfare arena, social welfare and healthcare, are crucial for addressing families' and children's needs in social, emotional, and physical healthcare situations. How child welfare workers are trained and how healthcare teams collaborate with other stakeholders in the child welfare system is crucial in meeting and sustaining the needs of families and children. Methods: We demonstrate two case examples, one focusing on enhanced learning tools through virtual reality (VR) and the other on strengthening collaborations between healthcare teams and the child welfare system. Results: For the VR training tool, 79\% of participants indicated they would recommend the VR learning tool as effective in developing skills in the child welfare workforce. In response to the learning collaborative project, child welfare participants reported positive impressions regarding collaborative practices while identifying system-level barriers to implementation. Conclusion: Findings from these two case studies provide insights from which to consider system development for designing and implementing sustainable improvements in child welfare approaches to families and children referred for suspected maltreatment.
\end{abstract}

Keywords: child welfare; workforce development; training; quality improvement

\section{Introduction}

Contemporary perspectives on child protection in the United States place the heavy burden of assuring child safety in the present and ameliorating child risks over time squarely in the jurisdiction of state child welfare agencies [1]. In contrast, historical perspectives highlight the multidisciplinary origins of child protection in this country [2,3]. Awareness of child maltreatment and the need for child protection grew in both social service and healthcare systems from shared roots early in the 20th century. Passage of the Child Abuse Protection and Treatment Act (CAPTA) in 1972, and reauthorizations over the intervening decades, cemented national and state commitment to child protection [4]. At the same time, this legislation translated into policies and practices assigned these two child-serving professional communities to sharply demarcated and nonoverlapping roles. The U.S. is currently re-evaluating the effectiveness of this siloed approach, noting that "Responsibility for protecting children must be shared among many sectors of the community, all working together, to strengthen prevention and early intervention, surveillance, child protective service (CPS) agency intervention, and cross-system collaboration" [1].

Child healthcare providers, alongside other mandated reporters, serve in a firstresponder role, recognizing and referring cases of suspected child maltreatment, while child welfare workers take up these referrals for investigation and intervention. This siloed approach may preclude collaborative efforts to identify and respond to caregiver risk factors 
and child vulnerabilities [5]. It also fails to assure continuity and support after investigation for suspected child maltreatment due, in part, to separate but equally restrictive privacy protections that serve as real and perceived barriers to longitudinal support for children at risk of maltreatment even after child welfare involvement. Training for caseworkers may emphasize privacy regulations without highlighting permissible opportunities to create a community safety net during an investigation for suspected maltreatment $[6,7]$.

Complicating this siloed approach, child welfare agencies nationwide struggle to keep up with the constant demand to develop and deliver a host of various training protocols intended to improve a caseworker's ability to provide needed services to support the vulnerable children and families they serve [8]. Federal Child and Family Service Reviews (CFSR) suggest that states experience higher quality caseworker performance when a strong training component is present [9]. However, no state has passed the CFSR to date, and the United States is currently still determining what will allow for effective engagement in these types of reviews. Therefore, while training intends to help systems and agencies deliver effective services, this does not guarantee effective service delivery.

In the United States, child welfare practice models aim to improve skill levels of their workforce yet often lack sufficient practice opportunities. An inability of many child welfare jurisdictions to measure skill acquisition and performance over time further compounds this issue of skill development. Sustaining positive outcomes in families served by child welfare systems is partly dependent on our ability to provide sufficient practice opportunities through evidence-based learning methods proven to develop a competent workforce. Sufficient practice opportunities are not only a signature pedagogy of social work and the helping professions [10], but central to skill development in various industries worldwide, including medicine [11], sports [12], and aviation [13].

Two disciplines that work in the child welfare arena, social welfare and child healthcare, are crucial for addressing families' and children's needs in social, emotional, and physical healthcare situations. How workers are trained and how healthcare teams can be engaged are crucial questions that need to be addressed to sustainably meet the needs of families and children. This article describes two projects for creating more competent and better functioning child welfare systems by using enhanced learning tools, such as virtual reality (VR), for training and strengthening collaboration between child welfare and healthcare professionals.

\section{Methods}

This article uses a case study framework to describe two projects highlighting collaborative and innovative designs for managing child welfare events for families and children. As noted by Creswell and Poth, a case study "involves the study of a case (or cases) within a real-life, contemporary context or setting" [14] (p. 96). The idea of a case study is that the case(s) are "bounded" either in setting or location [14] (p. 96). The qualitative methods used in case studies in medicine and the social sciences allow for an "in-depth understanding of the case" and are especially useful for identifying "patterns" that can be used to support general conclusions [14].

Thus, we examine two case studies for this article: one focused on using virtual reality (VR) training approaches designed to enable child welfare workers to reliably reach expertise, and one about collaborative training of child welfare and child healthcare workers to improve communication in real-world settings. These two case studies provide insights from which to consider system development for designing and implementing sustainable improvements in child welfare approaches to families and children referred for suspected maltreatment. Each case study provides an introduction and description of the project and a discussion about overall project findings.

\section{Child Welfare Training \& Deliberate Practice Training: Case Study \#1}

Numerous states use child welfare practice models to help improve service delivery efforts [14]. Practice models often share similar characteristics that aim to improve outcomes 
by showing workers how to provide best practice with sufficient competency in skills such as engaging, assessing, teaming, planning, and intervening $[8,15,16]$. Ironically, training on most practice models typically involves very little practice beyond a few role-plays and simulation experiences. Without skills practice during training, workers are left to develop the required skills while on the job.

Further complicating skill acquisition efforts, most child welfare agencies struggle to measure the existence of worker competency levels empirically. Without knowing the skill level of the workforce, an agency cannot know the effect of training approaches and what additional training their workers need to deliver services effectively [15]. Increased understanding of the competency level of necessary skills may enhance service delivery and positive outcomes for families served $[17,18]$.

In general, research on effective practices in child welfare is growing around issues of workforce and family outcomes; however, providing sufficient practice opportunities prior to working with families and assessing the competency level of workers to demonstrate effective practice in child welfare is not keeping pace $[19,20]$. Failure to provide sufficient practice opportunities for child welfare workers is comparable to sending an aspiring pilot in the air before adequate hours in the flight simulator. In a very literal manner, both risk putting others' lives at unnecessary risk.

While it is outside the scope of this section to review or identify all the efforts child welfare jurisdictions can make to remedy the shortage of sufficient practice opportunities, we provide a case example of how a federally-funded, public child welfare agency partnership with the University of Utah developed a learning tool designed to provide such practice opportunities to current and prospective child welfare workers. This tool also measures performance level, or skill change, over time through a deliberate practice experience.

\subsection{Theory of Deliberate Practice}

Ericsson's concept of deliberate practice began to make a significant presence in the literature in the late 1990s and today strongly supports the rationale for using field practicums for skill development when specific learning elements are used to guide the training experience. The Theory of Deliberate Practice (DP) provides a framework for reliably acquiring skills and progressing toward a level of expertise [21]. DP has been used to guide research in numerous fields, such as athletics [12], aviation [13], and medicine [11], to name a few. Federal funds in the United States are provided through the U.S. Department of Health and Human Services (USDHHS) to help cover the costs of training child welfare workers. These funds are made available, in part, through University-Public Agency contracts called Title IV-E partnerships. Like many undergraduate and graduate programs, Title IV-E partnerships utilize field practica, or field education, as a crucial component in preparing child welfare students for the field. These students experience virtually every facet of their assigned job while practicing the skills they learned in class and from their professional colleagues at a practicum site. However, these practicum experiences often serve as a more introductory exposure to the skills needed to be a fully competent child welfare worker. Therefore, students may currently only be introduced to the skills necessary to be an expert worker without being provided the proper skill practice or reliable method to progress toward expertise. DP can serve as the methodology and framework to reliably gain expert skill.

\subsection{Leveraging Technology}

In creating opportunities for expert skill development, DP can provide the framework and approach to learning, while VR can be leveraged to provide the necessary and accessible environments for skills practice. Though VR represents an established technology with a history of commercially available headsets that began in the late 1970s and early 1980s, social work has yet to fully incorporate VR technology that can be harnessed to enhance the workforce's training [22]. With the increasing prevalence of VR and decreasing costs, VR is making inroads into the social sciences, including child welfare [23]. Institutions 
such as Stanford's Virtual Human Interaction Lab (https:/ /www.stanfordvr.com/ projects / accessed on 1 July 2021), the University of Southern California's (USC) Institute of Creative Technology (https: / /ict.usc.edu / accessed on 1 July 2021), and the University of Utah's Virtual Social Work Trainer (https:/ /vswt.utah.edu/ accessed on 1 July 2021) are investigating prosocial uses for VR as a novel approach to training. In addition to its increased use in academia and research, VR has also garnered mainstream and commercial traction in a number of fields and workforce settings, as already mentioned. The commonplace use of VR is also visible in published trends/lists, such as the Gartner Hype Cycle of Emerging Technologies, which has not listed VR since 2017 [24]. The exclusion from the list indicates that VR is no longer a novel technology but has become more widespread. Current VR systems allow for constructing immersive and realistic environments that incorporate complex events in a reproducible manner with high degrees of fidelity [25]. VR also offers the ability to efficiently incorporate principles of DP necessary for expertise such as replicable/repeatable exercises, immediate feedback, and learning in chunks that mitigate risks for cognitive overload [26]. Given the availability of such VR technology and its ability to repeatedly produce the complex social environments necessary to skills practice, we feel it is logical for VR to fit into the human service field.

Based on the experiences of professional domains that have utilized VR extensively, and our own experiences developing an initial prototype specific to child welfare, realizing the benefits of VR to increase the effectiveness of child welfare workers requires attention on several important aspects. Such aspects include being developed based on evidence-based learning theories [23], or else VR will simply represent more technology for technology's sake. In other words, merely using VR does not ensure learning [27]. In addition, attention must be given to effective learning elements, particularly effective feedback combined with the use of multimedia to provide the necessary practice environments that facilitate expert-level performance $[27,28]$.

\subsection{Approach}

The Virtual Social Work Trainer (VSWT) is a suite of skills training modules [29], which provides child welfare workers with essential skills that are typically acquired only after beginning the job of social work. VSWT is being developed and designed by McDonald and Davis et al. at the College of Social Work, University of Utah (UofU) in partnership with the Games and Applications Lab (GApp), with the School of Entertainment Arts and Engineering (EAE), in collaboration with faculty from the UofU Health Systems Innovation \& Research (HSIR) Program.

One of the skills modules called Virtual Home Simulation (VHS) is a VR software program designed with Unity [30] and optimized for Windows and Mac operating systems as well as Facebook's Oculus Rift. VHS aims to improve child welfare workers' ability to assess possible "risk factors" and "protective factors" or "protective capacities" of caregiver(s) [31] involved in child welfare cases. VHS strives to enhance these necessary skills by providing learners with opportunities to repeatedly assess the presence of risk and protective factors in concert with immediate and meaningful feedback.

The primary focus of VHS is to increase skills of assessing possible risks and protective factors learners observe in the home environments, given the specific case circumstances for the home. At the time of this writing, there are four different VHS homes, each with its own unique set of circumstances that the user can refer to at any point during their assessment. The virtual case file for each home includes a Child Abuse and Neglect Report (CANR), which indicates all individuals involved. This CANR includes names and ages of children, caregivers, alleged perpetrators, and alleged victims of child maltreatment, as well as a brief narrative describing the reason(s) this family has come to the attention of the public child welfare agency.

Once participants review the case file, they can move about each home to assess items that may indicate risk or protection considering the specific case circumstances they read 
about in the case file. Figure 1 is an example of what the participants see at this point in the skills practice.

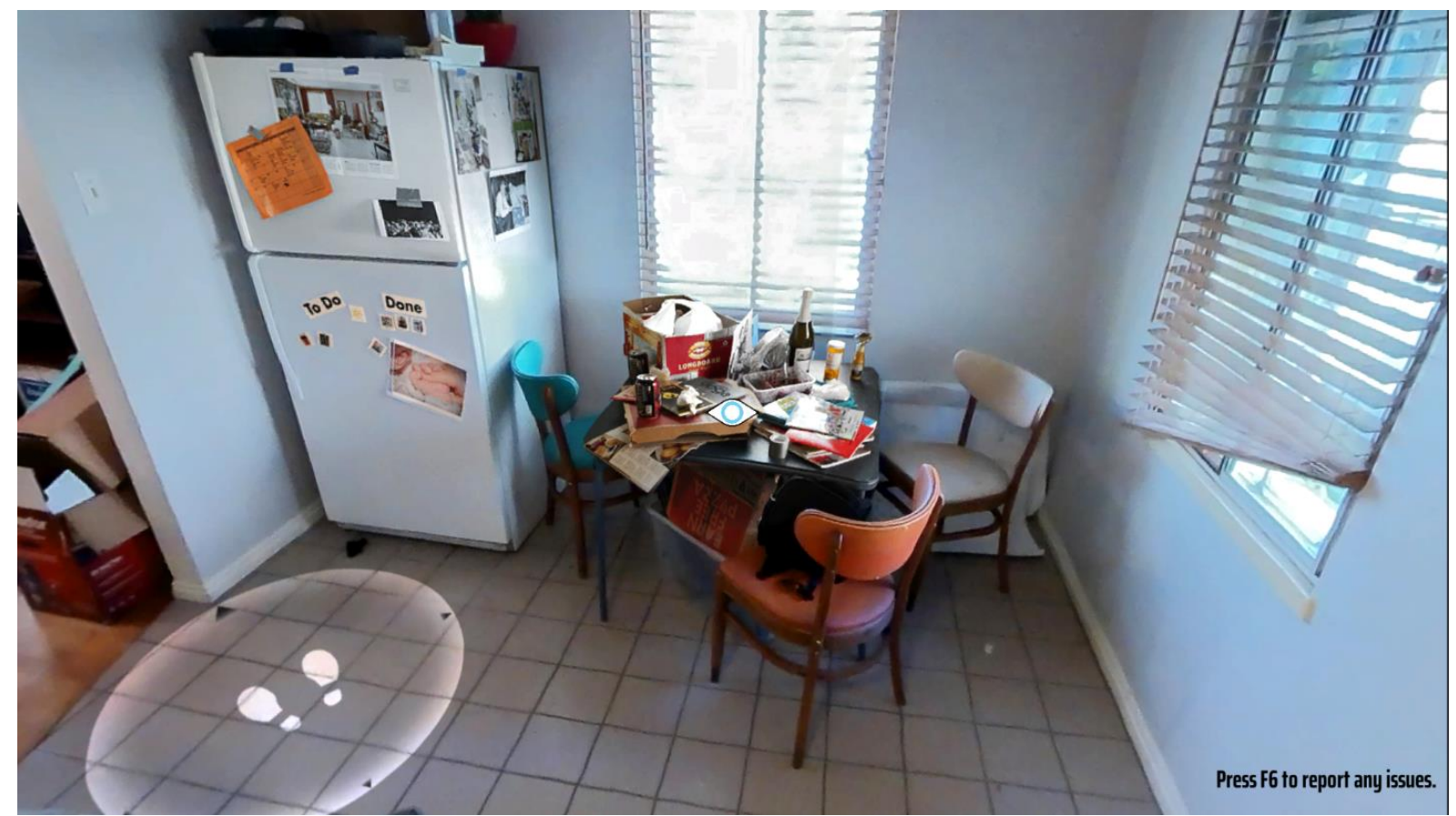

Figure 1. Participant View of VHS on Laptop.

Position markers with two shoe prints indicate various perspectives around the home. Participants move about the house by clicking on these markers. Some items allow a closer look, indicated by an eye symbol, as shown in the center of Figure 2. Left-mouse clicking the eye symbol brings the object into a close-up view. Figure 2 is an example of what the participant sees when zoomed in. This figure shows the interface where the participants indicate if any items may represent risk or protection and write a rationale for their decision.

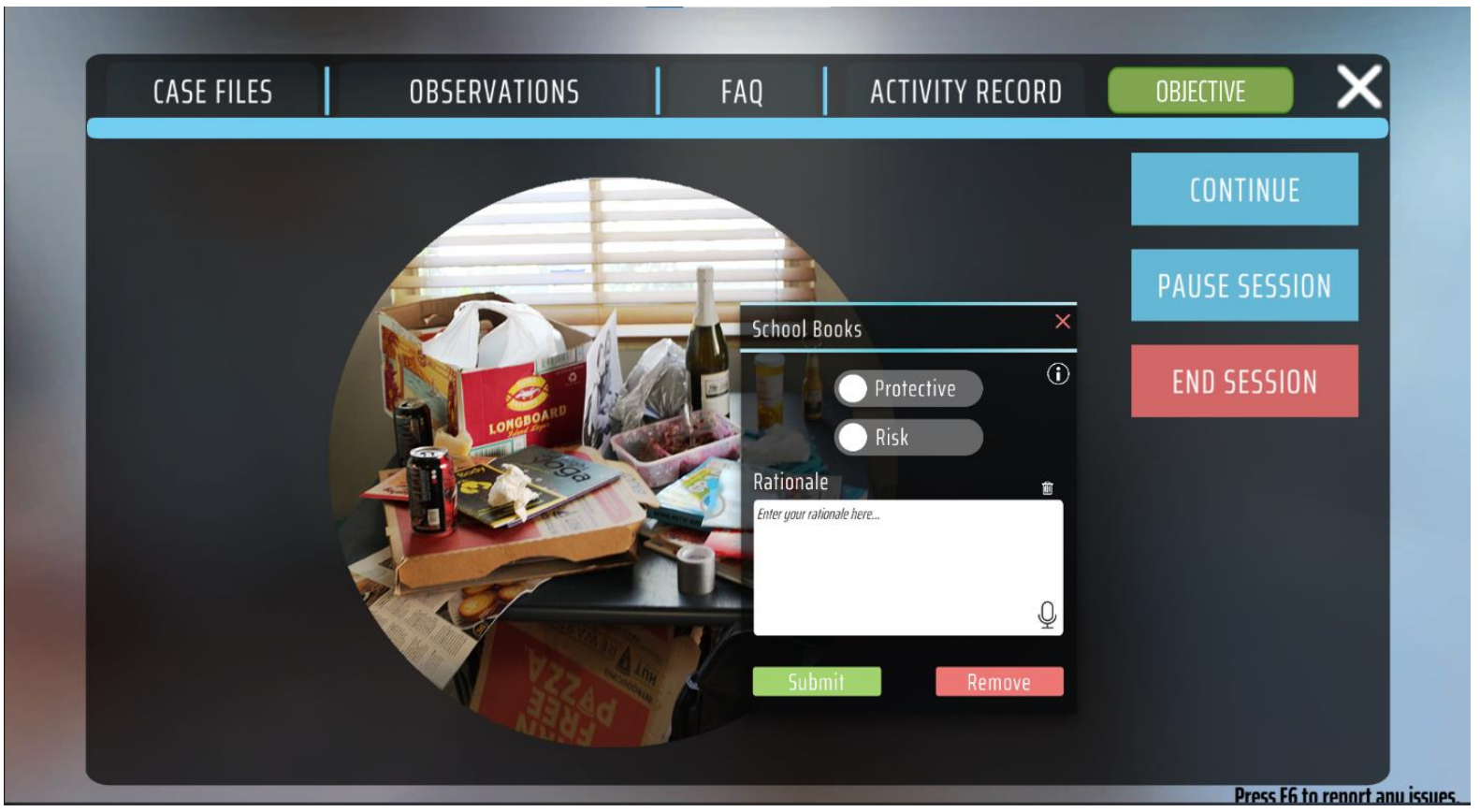

Figure 2. Decision-making Interface in VHS. 
As not every practicing individual is at the same skill level, VHS provides various modes or scaffolds designed to encourage learners to stretch beyond their current skill level. At the time of this writing, users can choose three different modes while using VHS: coached mode, free-practice mode, and evaluation mode.

Coached mode provides the highest level of structure and is designed for beginners. Coached mode intends to give the learner an experience as if a coach were beside them while navigating the house. Coached mode provides immediate feedback on every item in the house as the learner interacts with it, along with thought questions and other prompts to help learn to assess possible indicators of risk and protection. The free-practice mode is less structured and allows the participants to move about each home in whatever sequence they desire, and provides feedback on the entire home assessment at the end of each home practice session. Evaluation mode delivers a method for measuring the change in skill performance between a preassessment and a postassessment of one of the home levels in VHS throughout a pre-set timeframe. This last mode enables assessing the validity of VHS in building these target skills (see [22], for more details regarding design considerations of VSWT).

At the end of each practice session, participants are provided a summary score for their performance and a detailed report with specific feedback on whether child welfare experts felt items were more risk or protective in nature. As expertise can be the result of practicing specific behaviors over time if practiced correctly [32], this learning tool tracks the performance of each learner over time and provides an estimate of the skill level from Fundamental to Expert, and changes as learners consistently perform at higher and higher levels. Figure 3 shows the summary screen with the various aspects the learner sees about their performance for a specific practice session.

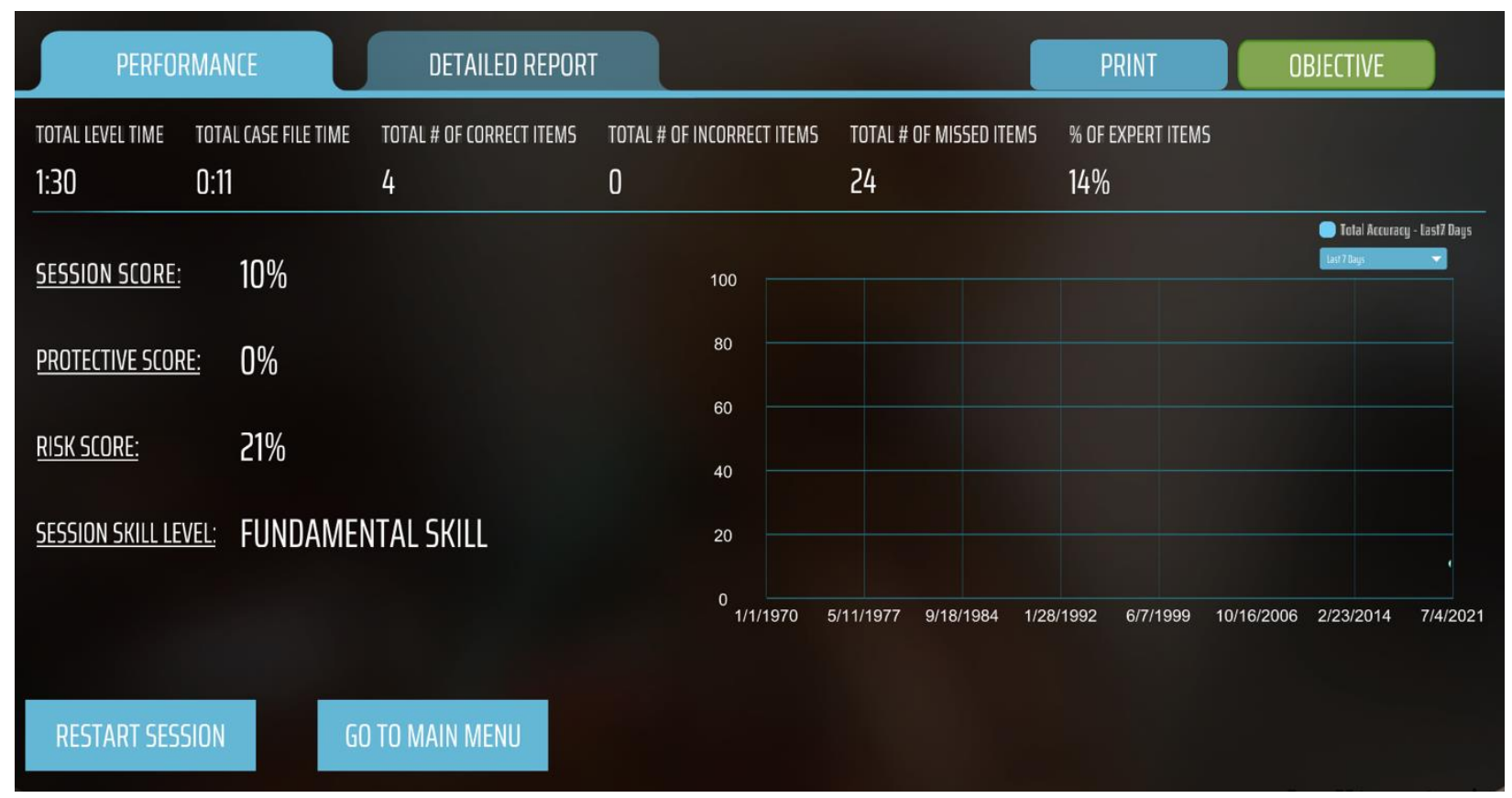

Figure 3. Individual Practice Session Summary Performance Screen.

Although VSWT-VHS is still in development, numerous child welfare jurisdictions across the United States are piloting it in their child welfare training curriculum. This launch speaks to the relevance and importance of such structured skills practice, or perhaps of the vital need for such skills practice.

A feedback survey is embedded in the various modes and gathers information on participant demographics and experience in child welfare and prior experience with VR technology. One of the questions on the feedback survey asks: "If someone asked you about the effectiveness of the Virtual Reality learning experience, would you recommend 
the learning to them?" Available options ranged from "too ineffective to recommend" to "very effective, so I would highly recommend it" on a 5-point Likert scale. Thalheimer refers to this approach as a meaningful step in determining learning effectiveness, called the Net Effectiveness Score (NES), in contrast to the less meaningful Net Promotor Score (NPS) that was not designed necessarily for learning [33].

Before exploring the impact on skill acquisition, it is essential to understand whether child welfare jurisdictions could embrace VHS as an effective learning tool. The NES score provides insight into this question's answer and suggests the likelihood of VHS motivating child welfare jurisdictions to leverage its potential. The results below focus on how a group of supervisors and trainers from a public child welfare agency $(n=33)$ in one western state responded to this NES question.

\subsection{Results}

This sample was derived from a convenience sample of child welfare supervisors, trainers, and administrators in the state of Montana's public child welfare agency who met predetermined benchmarks of expertise in the field. Participants were randomly assigned and assessed two homes within the VHS tool and completed a feedback survey throughout one afternoon during a statewide conference. Of the 33 participants, $79 \%(n=26)$ responded that they would recommend or highly recommend VSWT-VHS as an effective tool to others. Table 1 below shows the results of all participants on the NES.

Table 1. Net Effectiveness Score.

\begin{tabular}{|c|c|c|}
\hline \multicolumn{3}{|c|}{$\begin{array}{l}\text { If Someone Asked You about the Effectiveness of the Virtual Reality Learning Experience } \\
\text { Would You Recommend the Learning to Them? }\end{array}$} \\
\hline & $\mathrm{N}$ & $\%$ \\
\hline The learning experience was too ineffective to recommend & 0 & $\mathrm{~N} / \mathrm{A}$ \\
\hline $\begin{array}{l}\text { The learning experience was ineffective enough that I would be } \\
\text { hesitant to recommend }\end{array}$ & 0 & $\mathrm{~N} / \mathrm{A}$ \\
\hline $\begin{array}{l}\text { The learning experience was not fully effective, but I would } \\
\text { recommend it if improvements were made to the learning }\end{array}$ & 1 & $3.0 \%$ \\
\hline $\begin{array}{l}\text { The learning experience was not fully effective, but I would still } \\
\text { recommend it even if no changes were made to the learning }\end{array}$ & 6 & $18.2 \%$ \\
\hline The learning experience was effective, so I would recommend it & 21 & $63.6 \%$ \\
\hline $\begin{array}{l}\text { The learning experience was very effective, so I would highly } \\
\text { recommend it }\end{array}$ & 5 & $15.2 \%$ \\
\hline
\end{tabular}

The final question on the survey was an open-text solicitation for any additional comments, reactions, or feedback supporting their recommendation selection. These select statements provide further insight into VSWT-VHS as having supported the experience and shed light on possible improvements on usability and relevance. All feedback was grouped into similar categories, with the select statements below representing all the other comments not provided here. These comments include both positive statements as well as statements that indicated areas for improvement.

Comments that were considered generally positive were:

- "I believe that this would be a great tool in order to talk through small details [sic] of a case based on real observations instead of trying to have worker "imagine" or recall something they have seen".

- "Would be great for people before they interview for the job".

- "This would be helpful at looking at child injuries as well".

- "I think this would be a great tool to use for training new workers, I also feel that if something similar could be used during interviewing new applicants for workers this 
would help with retention, hiring the right people for the work, and giving applicants a real idea of what this work involves".

- "I loved it and hope that it can continue to be used as a tool".

While both the NES scores regarding recommended use of VHS and open text feedback were largely positive, the qualitative data collected also captured challenges to VHS/VR, including areas that could be improved. It should be noted that no participant indicated the experience as "too ineffective to recommend" or even that the learning was "ineffective enough" that they would be "hesitant to recommend". Therefore most of the open text feedback featured positive statements regarding VHS and steps toward improvement as opposed to general dislike/discomfort with the tool.

Statements regarding how to improve the tool and the user experience were:

- "I think it could be generally helpful, but it only shows enough to know where to ask more questions about a lot of things".

- "The Virtual Home Simulation was effective and would be a great tool to train staff. I found it difficult to identify protective factors outside of pictures and books. More safety risks, especially regarding drug paraphernalia hiding in the rooms would be valuable to teach what to look for with new and experienced staff".

- "There were many aspects/items which could have been to varying degrees of importance. The scale allows for some variability, but I didn't feel like it was fully accessible. I [sic] one home a number of items COULD have suggested this or that characteristic, which honestly could be protective or concerning. It may be nice to have a continuum of concern/protective to be able to slide so that something could be neutral".

- "There should be some way to talk about concerns as we are assessing the whole picture ... so for example what about pictures, what about age appropriate toys ... why do adults have everything and kids are lacking".

- "It would be valuable to have an option of clicking areas and tagging them as "would seek more information" and then document why and what information would be necessary to determine if that item or area of the home was a risk or not".

\subsection{Lessons Learned/Next Steps}

Given that very few participants were experienced with VR before the training and qualitatively reported not being very comfortable with this type of technology prior to using it, these results are quite positive. The fact that just under $80 \%$ indicated they recommend or highly recommend VSWT-VHS as an effective learning tool also supports the implication that aspects of VSWT-VHS do not appear to suppress learning or distract from the task at hand, as can be the case with new and unfamiliar, perhaps clunky, technology. The implication of the effectiveness of VHS as an effective learning tool is further strengthened by the fact that of the 33 participants, no one indicated the experience was "ineffective" or "ineffective enough that [they] would be hesitant to recommend". The lowest rating on the five-point Likert scale was a three, where one respondent $(3 \%)$ indicated that while they felt it was "not fully effective", they would still "recommend it if improvements were made". This conclusion is supported by the fact that throughout the more negative comments, they still primarily focused on what would make the tool more meaningful or effective from the participant's perspective.

VSWT's evidence-based learning design holds promise for enabling human services workers to reach a level of competence prior to on-the-job performance. The workforce development efforts of child welfare agencies, providing regular, consistent skills practice, with expert feedback, may elevate workers' expertise and, in turn, better support sustained outcomes for the families served by the child welfare system.

Beyond the intended use of VHS as a method for reliably developing competency, jurisdictions that have begun to pilot VHS are reporting other promising benefits that we had not anticipated. For example, VHS has served as a realistic job preview. Several jurisdictions also report VHS helps increase trainees' understanding of personal biases that can interfere with objectively assessing indicators of risk or protection. 
In the next year, the efficacy of VSWT-VHS in building assessment skills will be compared to training as usual. Following this study, we plan to conduct a longer-term study that focuses on connecting improvements in skills after training in VSWT-VHS to improved proximal family outcomes, such as increased engagement and willingness to identify and complete service plan goals.

VHS is currently being implemented in a number of different states, both at the preservice and in-service sides. VHS aims to meet the diverse needs from region to region through the data collected, which informs the development and ongoing evolution of expert consensus on feedback within the tool. For example, VHS has the framework to curate algorithms based on experts in any given region. This means that when participants engage with the tool and receive feedback, it is possible that the feedback they receive is tailored to a consensus of experts only from within the same jurisdiction as the learner. Furthermore, VHS is designed to easily adapt to and integrate into current training efforts that leverage the expertise/experience of trainers and instructors to serve as a tool to enhance skills practice.

Some limitations of this current study include the small sample at a single point in time. The final sample size would have undoubtedly been larger without some technological limitations we have since designed into the software. For example, several users did not realize how much power the graphics card required to display the 360-degree virtual environment, which drained the battery far quicker than anticipated. This prematurely ended their assessment experience due to a dead battery and not enough outlets in the conference room. Finally, while these results may be largely positive, they do not imply actual effectiveness in skill development or transfer of target skill to the field. Future studies will focus on the effectiveness of this learning experience and whether any increase in skill transfers to the field or positively impacts the outcomes of families served by users of VSWT-VHS.

\section{A Learning Collaborative for Child Welfare Workers and Child Healthcare Providers: Case Study \#2}

The American Academy of Pediatrics defines a medical home for children as an outpatient medical clinic characterized by family-centered, continuous, comprehensive, coordinated, compassionate, and culturally effective care [34]. High-quality child healthcare, operationalized in practice as the family-centered medical home [35], may ameliorate the impact of existing childhood adversities and slow accumulation of new adversities experienced by children with a history of maltreatment $[5,36]$. This longitudinal, trustbased relationship has been identified as a potential resource for children at risk for abuse. Integration of the pediatric medical home with child abuse prevention programs was first proposed in 1985 [35]. Subsequent research described the association between anticipatory guidance from a trusted child healthcare provider and changes in parent behaviors related to practices such as infant sleep safety, car seat use, and gun storage [37]. Increased engagement with primary healthcare providers on these topics has been associated with lower unintentional injury rates [38]. Screening for, and responding to, social risk factors in the pediatric medical home has been demonstrated to reduce referrals for suspected maltreatment $[39,40]$. The strength of scientific evidence linking childhood adversity and toxic stress to disruptions in development across biological systems, and to disparate health outcomes over the lifespan, has prompted increased attention to child maltreatment and social determinants of health in the family-centered medical home [41,42]. The biology of childhood adversities and toxic stress is evident among children with recent histories of child welfare involvement. Child-welfare-involved children have clinically important reductions in health-related quality of life, comparable to children with chronic illnesses such as asthma, attention deficit disorder, or diabetes, and each additional childhood adversity experienced is associated with further reduction in child well-being [43,44]. Without communication between child health and child welfare systems, healthcare providers are likely to be unaware of child welfare involvement in a household, limiting the effectiveness of the medical home in shifting this trajectory for children with the highest social risks. 
The lack of cross-sector collaboration between child healthcare providers and child welfare caseworkers grows from policy, practice, and professional cultures. This ensures that we are missing opportunities to slow or stop the accumulation of childhood adversities, childhood traumatic stress and child maltreatment for children with a history of child welfare involvement. For many children referred to child welfare agencies for suspected child maltreatment, engagement with interventions to improve social determinants of health and well-being is limited. Less than half of children remaining in the home after substantiation receives post investigative services to ameliorate identified risk factors continuing beyond the time-limited child welfare investigation [45]. Even when provided, post investigative services may have limited effectiveness in reducing risk. Although reducing exposure to childhood adversities after abuse is associated with meaningful improvements in child well-being, the prevalence of childhood adversities typically persists in the years following CPS involvement in a home [46,47]. These findings are captured in the qualitative experiences of families who describe unmet needs after CPS involvement: "What about the families where there is no abuse left? I mean, sometimes they need help too. Even though there's no physical abuse left, they still need resources and stuff to hold them" [48].

Multiple challenges to cross-sector collaboration were identified by an expert multidisciplinary panel convened in 2008 [49]. This panel was initiated by healthcare providers calling for increased transparency in outcomes of referrals to child welfare agencies [5,50]. Panelists described a tension between the mandates for child welfare agency involvement when child maltreatment is suspected and the goal of continuity in the relationship between a primary healthcare provider and a child's family [51]. The lack of reliable collaboration during and after a referral to child welfare was cited as a key barrier to reporting suspected maltreatment by primary care pediatricians. The perception that child welfare involvement might not improve outcomes for a child at risk was a significant concern for referring healthcare providers. The panel also recognized that challenges experienced by child welfare caseworkers received less attention; these were critical to understanding the barriers to collaborative practice [52]. State laws regarding the protection of child welfare information, even to medical referents, might limit the information provided to a healthcare provider. Repeated but inaccurate invocations of the Health Insurance Portability and Accountability Act's (HIPAA) privacy laws by child healthcare providers unwilling to share information unnecessarily frustrated advances for collaboration by child welfare caseworkers [53]. Finally, implicit or explicit assumptions around professional hierarchies may create self-reinforcing barriers to effective and collegial cross-sector communication in protecting a child at risk for maltreatment.

The emergence in 2009 of new a new medical subspecialty—Child Abuse Pediatricspromised to advance collaborative practice in evaluating and responding to these complex cases $[54,55]$. A subspecialty pediatric workforce fully engaged in the multidisciplinary investigation of suspected child maltreatment advanced the evidence-based medical evaluation of children presenting with concerns for suspected child maltreatment [56-59]. Unfortunately, it is not clear that a child abuse subspecialty has advanced collaborative practices between child welfare and the pediatric medical home. By serving as a trusted medical consultant to primary healthcare and child welfare, Child Abuse Pediatricians may unintentionally reduce incentives to build bridges between these traditionally siloed professions [60]. In 2015, the Presidential Commission to Eliminate Child Abuse and Neglect Fatalities (CECANF) identified professional siloing as a significant barrier to preventing severe and fatal maltreatment, and called for increased collaboration and information sharing between child welfare, law enforcement, and child healthcare [1]. Our experience suggests that many of these challenges persist, largely unchanged, to the current moment.

Despite a shared commitment to child well-being, there is little precedent for collaboration between child welfare and child healthcare sectors in the U.S. Child Protective Services (CPS) caseworkers often have little knowledge of ongoing health concerns for a child; pediatric healthcare providers are frequently unaware of CPS involvement in a household. Multiple barriers to the interdisciplinary collaboration of these social institutions exist. 
These include policies protecting the privacy of child health records and child welfare histories, cloistered traditions of independent professional cultures, and assumptions around household preferences for collaboration between child health and child welfare sectors. These barriers stifle innovations in integrating care and improving outcomes for children with a history of maltreatment. We have undertaken a series of intersecting projects to accomplish a shared goal of improved child healthcare and child welfare collaboration. Our efforts to advance a more holistic understanding of child welfare and child protection in our state have resulted in incremental successes along with instructive failures, and highlight opportunities for continued innovation in the realm. This case study reflects the first project undertaken to advance these goals.

\subsection{A Learning Collaborative Model for Child Healthcare and Child Welfare Professionals}

The Learning Collaborative (LC) is a well-described educational intervention designed for quality improvement within healthcare systems, bringing together healthcare teams over 6-12 months to improve care and outcomes for a specified problem within a healthcare practice or community [61]. Traditionally, these teams participate in shared learning sessions to disseminate existing knowledge about the identified problem across multiple sites over the project timeframe. Between learning sessions, sites use rapid plan-do-study-act (PDSA) cycles to implement, evaluate, and adapt this shared knowledge into measurable practice improvements at individual sites with support from a quality improvement coach In the past years The Utah Pediatric Partnership to Improve Child Healthcare Quality (UPIQ) has used this process to improve primary care management of childhood obesity, adolescent depression, asthma, and autism [62-65]. There are promising large-scale adaptations of the LC model to community settings, working to develop and strengthen interdisciplinary collaboration in providing evidence-based prevention and intervention programs for children and families with high social needs [66,67].

\subsection{Approach}

Building on these examples, the UPIQ team proposed an LC to bring together child healthcare and child welfare professionals for a unique multidisciplinary 9-month learning collaborative on childhood adversities, abuse, and neglect [6]. UPIQ leadership worked with child abuse pediatricians, foster care medical providers, and trauma-focused mental health specialists to develop two half-day learning sessions for a multidisciplinary audience. The primary goal of these learning sessions was to improve recognition of adverse childhood experiences (ACE) and traumatic stress in work with children and families with high social risks. These sessions were accomplished through lectures, discussion groups, and "speed dating" sessions in which teams met with community resource providers focused on childhood adversities and traumatic stress. A second goal was to increase cross-sector understanding of primary healthcare providers and child welfare caseworkers to improve trust, confidence, and collaboration. This linkage was accomplished through formal didactics on child protection and the medical home, shared tabling to facilitate informal cross-sector interactions, and opportunities for medical teams to participate in brief immersion experiences with child welfare partners.

Nine primary care pediatric practices and one regional child welfare office were recruited to participate in the LC. Healthcare teams (including physicians, advanced practice providers, and case managers) were recruited through established UPIQ communication with primary care pediatricians in the community. They had the opportunity to earn Maintenance of Certification credits for participating, a requirement for medical board certification in the U.S. The child welfare team (including child welfare supervisors and child protection caseworkers) was selected by state administrators based on location and capacity to take on an innovative practice. Site-specific quality improvement projects for both pediatric and child welfare teams focused on screening for, and responding to, adverse childhood experiences and traumatic stress symptoms. Teams elected to implement the Traumatic Experiences Questionnaire (TEQ), a screening tool for childhood traumatic stress 
developed at the University of Utah, or Safe Environment for Every Kid (SEEK), a screening tool for social risk factors previously demonstrated to reduce child welfare referrals for suspected maltreatment $[39,40]$. Teams were introduced to both screening tools during the first learning session and encouraged to select the one that matched the interests and capacities of each site. PDSA cycles encouraged iterative changes in practice from week to week based on experiences with screening and response within each setting. System-level quality improvement efforts were undertaken to break down barriers to child healthcare and child welfare communication and collaboration in medically referred cases of suspected child abuse. The focus of these efforts included (1) allowing the state intake office to direct referrals for suspected child maltreatment from participating pediatric clinics to the collaborative child welfare office, rather than through usual assignment protocols, and (2) developing a case closure letter to be sent to medical referents with information regarding risk factors, resource referrals, and case outcomes relevant to ongoing care after child welfare involvement ends.

\subsection{Results}

Traditional evaluation of LC programs relies on tracking of the uptake of new screening tools or clinical interventions. Implementation of site-specific screening for traumatic stress and adversity was high in both child healthcare and child welfare teams. For the pediatric practices, rates of screening for social needs and traumatic stress improved measurably. Unfortunately, tracking of implementation in the child welfare setting was not systematically recorded. In addition to these traditional quality improvement measures, our team conducted and analyzed four focus groups with eight child welfare caseworkers, two child welfare supervisors, five primary care pediatricians, and five primary care clinic staff [6]. Focus groups were held separately to reduce the influence of real and perceived hierarchies and were moderated by an experienced qualitative research assistant via web conference. Audio recordings were transcribed and analyzed by two investigators for themes emerging within and across participating groups. Healthcare providers expressed new insights into the high prevalence of childhood adversities in a general pediatric population. "It was a real eye-opener to me how many people were very honest in answering those questions, and it led to longer conversations ... I think we'll see longer lasting effects from these questionnaires because families are going to be more open with us about the real struggles in their lives". The child welfare team chose to adopt SEEK, a screening tool assessing social risk and material needs. Although tracking the screening uptake within child welfare practice proved difficult, qualitative reflection suggested that the screener offered unanticipated opportunities to work with families to address basic needs beyond the immediate question of child maltreatment. As noted by one child welfare supervisor, "If we're able to provide them a resource, a positive thing ... we've helped to build one protective factor by helping them with a resource". Reflecting the limitations associated with wholesale adoption of screeners validated only within a healthcare setting, however, caseworkers struggled at times with meaningful responses to disclosures elicited by the screening tool: "Some of the questions on there were, you know, 'Do you have a smoke detector? Our families are, I hate to say, so far beyond that, but they are ... I mean we have feces all over the floor, we have mold, we have stuff like that. A smoke detector sometimes is on the very back of the list. You know what I mean?"

Moments of cross-sector collaboration at the individual level surfaced throughout the course of the LC. Healthcare teams reflected on a better understanding of and increased trust in the child welfare system, while child welfare teams described new recognition of the significance of continuity within the family-centered medical home. "It really helped us solidify some relationships with CPS", noted one physician. Caseworkers finally felt heard by medical providers more often protected by multiple layers of clinical staff: "We had the chance to talk with the providers ... I think that's when they finally wrapped their brain around the fact of the confidentiality and where our hands got tied on certain things. They were getting frustrated with trying to communicate with us about things and we were 
getting frustrated because we couldn't voice those things to them". As might be expected from a relatively brief intervention, however, these "aha moments" were limited. Even in recounting episodes of incremental progress, participants from each group reasserted the same frustrations with communication described over the previous decade, citing divergent expectations, limited data-sharing, and professional hierarchies as challenges to collaborative practice. The persistence of these frustrations underscored the critical need for system-level changes to support small but significant advances in cross-sector collaboration at the individual level. While we identified no negative consequences from these practice improvements, focus group participants reminded us that collaborative practice carries unmeasured risks, including potential for breaches in confidentiality, higher staffing expectations, and identification of social needs for children and families, such as housing or employment, that neither child welfare nor healthcare has the capacity to address within the U.S. context.

The LC also highlighted the folly of simply transposing practice improvement methods established in one professional culture to a very different system. UPIQ organizers, accustomed to the flexible decision-making within an individual healthcare setting did not fully anticipate the challenge of initiating system-wide practice change within a large state agency. Tracking and routing calls from participating healthcare clinics to a single child welfare office was not always successful, yet was met with appreciation when achieved. Development of a new, information-rich case closure letter to be provided to a medical referent required methodical review of state law, iterative revisions to letter content, integration of new forms into the state child welfare information system, and training of caseworkers on use of the letter. These steps were only achieved in the final weeks of the LC. While too late to be fully integrated during the LC, medical providers appreciated the shared information when it finally arrived: "I got a letter from CPS to follow up on a case where they'd actually gone in and done some preventive strategies and I was really pleased that they were taking that on. I've seen them do this in a couple of cases recently". This medical referent letter persists in practice policy for the Utah Division of Child and Family Services: "I think that one of the big things that's come out of this is that closure letter, you know? Because there's always been that bit of confidentiality, and so the closure letter that they got approved for the UPIQ project, you know, gives more information about the particular child, and the finding, and that we're referring them for services. It really engages those doctors so they can say, okay, good, I'm still [going] in the right direction and we'll still continue to work with the family". These lessons have informed the cross-sector collaborations which have grown from this first pilot project. We have adapted methods from community-based participatory research to assure a shared understanding of resources and priorities in each practice improvement effort. While this approach requires time and energy, we hope that it will result in sustained improvements.

\subsection{Lessons Learned/Next Steps}

This cross-sector learning collaborative was a first step by a single state to respond to years of academic research and expert panel pronouncements on the need for a multidisciplinary response to child maltreatment. The collaborative grew from the resources available to our community, and lessons were learned at each step. Reliance on a model of quality improvement developed for healthcare clinics did not always translate well to the highly regulated realities of a state agency. Expectations for system-level policy change may have been overly ambitious. Development of trust and mutual respect at the individual level might have been carried out with increased intentionality. Despite these limitations, this experience lays the groundwork for continuing efforts to improve collaboration between child healthcare and child welfare to recognize and respond to child maltreatment.

\section{Conclusions}

Each of the innovative cases presented in this article highlights the need for more skill development and collaborative work efforts. Families and children are more than 
a child welfare or healthcare case, their needs are across systems. In conversations with parents, they note that the effort it takes to reclaim their lives and their children's lives is quite onerous since the various systems they must deal with do not speak to one another. In addition, caseworkers in child welfare sometimes do not have a depth of competency to effectively manage a family's issues, which further highlights the need for having cross-sector support of professionals with the adequate skills to help the families succeed.

In Case \#1, the development of three VR levels allows child welfare workers to improve their skill levels continuously. Building competency in assessing home environments for the child welfare workforce through repeated practice opportunities carries great promise toward an increase in communication with families and healthcare providers. As the understanding of risks and protective factors increases, child welfare workers can better understand what other professionals can assist in reducing risks for families and children. These efforts can improve collaborations across professions in a way not fully realized.

In Case \#2, team building work in the child welfare and healthcare contexts is crucial for identifying methods for professionals to collaborate in providing care for families and children. The concept of LC leads to quality of care and better communication based on evidence from research and the field.

Providing repeated practice opportunities to become experts in child welfare may also help elevate the child welfare profession and move the needle toward seeing such professionals as first responders, as are many of our healthcare providers. In a very real sense, lives are at stake every day, both in healthcare and child welfare systems in the United States and other countries. Increasing the competencies and collaborative abilities of these agencies holds promise in better meeting the needs of the children and families served, and better sustaining their stability as family units.

Author Contributions: Conceptualization, C.J.F., C.M. and K.A.C.; methodology, C.M. and K.A.C.; software, C.M.; validation, C.M. and K.A.C.; formal analysis, C.M. and K.A.C.; investigation, C.M. and K.A.C.; data curation, C.M. and K.A.C.; writing-original draft preparation, C.J.F., C.M., K.A.C., C.B., M.J.D.; writing—review and editing, C.J.F., C.M., K.A.C., C.B., M.J.D.; project administration, C.M. and K.A.C.; funding acquisition, C.M., K.A.C., M.J.D. All authors have read and agreed to the published version of the manuscript.

Funding: VSWT is funded through the Utah Title IV-E Training and Education Grant, Contract No. A02433, in partnership with the Social Research Institute, University of Utah. The Learning Collaborative Project was supported by a Children's Health Insurance Program Reauthorization Act (CHIPRA) Quality Demonstrations grant (1Z0C030547-01-0) awarded by the Centers for Medicare and Medicaid Services (CMS) to the Utah Medicaid Program (PI Norlin). Additional funding for the Learning Collaborative Project was provided by the Eunice Kennedy Shriver National Institute of Child Health and Human Development of the National Institutes of Health under award number K23HD059850 (PI Campbell).

Institutional Review Board Statement: The study was conducted according to the guidelines of the Declaration of Helsinki, and approved by the Institutional Review Board (or Ethics Committee) of the University of Utah and/or the Utah Department of Human Services. The VSWT study protocol numbers and approval dates are: IRB_00123571 approved on 6 February 2019. The Learning Collaborative Project IRB approval was obtained from the University of Utah (IRB_00077820, 11/25/2014) and the Utah Department of Human Services (0559, 12/14/2014).

Informed Consent Statement: For both case studies, informed consent was obtained for all participants involved in the studies.

Data Availability Statement: The data for these case studies are not publicly available at this time and will not be shared.

Conflicts of Interest: The authors declare no conflict of interest. 


\section{References}

1. Commission to Eliminate Child Abuse and Neglect Fatalities. Within Our Reach: A National Strategy to Eliminate Child Abuse and Neglect Fatalities. Government Printing Office, 2016. Available online: http:/ /www.acf.hhs.gov/programs/cb/resource/ cecanf-final-report (accessed on 1 July 2021).

2. Heins, M. The 'Battered Child' Revisited. JAMA 1984, 251, 3295-3300. [CrossRef] [PubMed]

3. Myers, J.E. A short history of child protection in America. Fam. Law Q. 2008, 42, 449-463.

4. The Child Abuse Prevention and Treatment and Adoption Act, 42 U.S.C. 5101 et seq; 5142 U.S.C 5116 et seq. Available online: https:/ / uscode.house.gov/view.xhtml?req=(title:42\%20section:5106a\%20edition:prelim) (accessed on 30 January 2019).

5. Flaherty, E.; Legano, L.; Idzerda, S.; Council on Child Abuse. Ongoing Pediatric Health Care for the Child Who Has Been Maltreated. Pediatrics 2019, 143, e20190284. [CrossRef]

6. Campbell, K.A.; Wuthrich, A.; Norlin, C. We Have All Been Working in Our Own Little Silos Forever: Exploring a Cross-Sector Response to Child Maltreatment. Acad. Pediatr. 2020, 20, 46-54. [CrossRef] [PubMed]

7. Melton, G.B. Mandated reporting: A policy without reason. Child Abus. Negl. 2005, 29, 9-18. [CrossRef]

8. Children's Bureau. ACF Vision, Mission, \& Values. @ACFHHS. 2017. Available online: https://www.acf.hhs.gov/about/acfvision-mission-values (accessed on 17 October 2017).

9. Flower, C.; McDonald, J.; Sumski, M. Review of Turnover in Milwaukee County Private Agency Child Welfare Ongoing Case Management Staff; Child Welfare Associates, LLC: Wheaton, IL, USA, 2005.

10. Council on Social Work Education. 2015 Educational Policy and Accreditation Standards: For Baccalaureate and Master's Social Work Programs; CSWE: Alexandria, VA, USA, 2015.

11. Hashimoto, D.A.; Sirimanna, P.; Gomez, E.; Beyer-Berjot, L.; Ericsson, K.A.; Williams, N.N.; Darzi, A.; Aggarwal, R. Deliberate practice enhances quality of laparoscopic surgical performance in a randomized controlled trial: From arrested development to expert performance. Surg. Endosc. 2015, 29, 3154-3162. [CrossRef]

12. Pagé, C.; Bernier, P.-M.; Trempe, M. Using video simulations and virtual reality to improve decision-making skills in basketball. J. Sports Sci. 2019, 37, 2403-2410. [CrossRef]

13. Hays, R.T.; Jacobs, J.W.; Prince, C.; Salas, E. Flight Simulator Training Effectiveness: A Meta-Analysis. Mil. Psychol. 1992, 4, 63-74. [CrossRef]

14. Creswell, J.W.; Poth, C.N. Qualitative Inquiry and Research Design: Choosing among Five Approaches, 4th ed.; Sage Publications: Los Angeles, CA, USA, 2018.

15. Center for the Study of Social Policy. For the Welfare of Children: Lessons Learned from Class Action Litigation; ERIC Clearinghouse: Washington, DC, USA, 2012.

16. McCarthy, J. Guide for Developing and Implementing Child Welfare Practice Models; National Child Welfare Resource Center for Organizational Improvement, University of Southern Maine, Muskie School of Public Services: Portland, ME, USA, 2012.

17. Barbee, A.P.; Christensen, D.; Antle, B.; Wandersman, A.; Cahn, K. Successful adoption and implementation of a comprehensive casework practice model in a public child welfare agency: Application of the Getting to Outcomes (GTO) model. Child. Youth Serv. Rev. 2011, 33, 622-633. [CrossRef]

18. Fixsen, D.L.; Naoom, S.F.; Blase, K.A.; Friedman, R.M.; Wallace, F. Implementation Research: A Synthesis of the Literature; FMHI Publication \#231; The National Implementation Research Network, Louis de la Parte Florida Mental Health Institute, University of South Florida: Tampa, FL, USA, 2005.

19. Balas, E.A.; Boren, S.A. Managing Clinical Knowledge for Healthcare Improvement. Yearb. Med. Inform. 2000, 9, 65-70.

20. Fixsen, D.L.; Blase, K.; Metz, A.; Dyke, M.V. Statewide Implementation of Evidence-Based Programs. Except. Child. 2013, 79, 213-230. Available online: http:/ / search.ebscohost.com/login.aspx?direct=true\&db=pbh\&AN=84513030\&site=ehost-live (accessed on 1 July 2021). [CrossRef]

21. Ericsson, K.A.; Krampe, R.T.; Tesch-Römer, C. The role of deliberate practice in the acquisition of expert performance. Psychol. Rev. 1993, 100, 363-406. [CrossRef]

22. Davis, M.J.; Raines, J.A.; Benson, C.L.; McDonald, C.H.; Altizer, R.A. Toward a framework for developing virtual reality skills training in human services. J. Technol. Hum. Serv. 2021, 39, 295-313. [CrossRef]

23. McDonald, C.; Davis, M.; Benson, C. Using Evidence-Based Learning Theories to Guide the Development of Virtual Simulations. Clin. Soc. Work. J. 2021, 49, 197-206. [CrossRef]

24. Gartner, G. 5 Trends Emerge in the Gartner Hype Cycle for Emerging Technologies. 2018. Available online: https://www.gartner. com/smarterwithgartner/5-trends-emerge-in-gartner-hype-cycle-for-emerging-technologies-2018/ (accessed on 1 July 2021).

25. Jerald, J. The VR Book: Human-Centered Design for Virtual Reality; Morgan \& Claypool Publishers: San Rafael, CA, USA, 2015.

26. Chandler, P.; Sweller, J. Cognitive Load Theory and the Format of Instruction. Cogn. Instr. 1991, 8, 293-332. [CrossRef]

27. Clark, R.C.; Mayer, R.E. E-Learning and the Science of Instruction: Proven Guidelines for Consumers and Designers of Multimedia Learning, 2nd ed.; Pfeiffer/John Wiley \& Sons, 2008; Available online: http://search.ebscohost.com/login.aspx?direct=true\&db= psyh\&AN=2007-18379-000\&site=ehost-live (accessed on 1 July 2021).

28. Ericsson, K.A.; Charness, N.; Feltovich, P.J.; Hoffman, R.R. The Cambridge Handbook of Expertise and Expert Performance; Cambridge University Press: Cambridge, UK, 2006. [CrossRef]

29. Social Research Institute; Games and Applications Lab. Virtual Social Work Trainer, Version 02_10_21; Computer Program; Unity. 2021. Available online: https:/ /vswt.utah.edu (accessed on 1 July 2021). 
30. Unity Technologies. Unity. 2021. Available online: https://unity.com/ (accessed on 1 July 2021).

31. Capacity Building Center for States. Protective Capacities and Protective Factors: Common Ground for Protecting Children and Strengthening Families. 2020. Available online: https:// capacity.childwelfare.gov/pubPDFs/cbc/protective-factors-capacitiescp-00052.pdf (accessed on 1 July 2021).

32. Ericsson, K.A.; Hoffman, R.R.; Kozbelt, A. The Cambridge Handbook of Expertise and Expert Performance; Cambridge University Press: Cambridge, UK, 2018.

33. Thalheimer, W. Replacement for the Net Promoter Score-For Learning Assessments. 2018. Available online: https://www. worklearning.com/2018/01/09/replacement-for-the-net-promoter-score-for-learning-assessments/ (accessed on 11 February 2021).

34. American Academy of Pediatrics. AAP medical home initiatives for children with special needs project advisory committee: The medical home. Pediatrics 2002, 110, 184-186. [CrossRef]

35. Sia, C.; Tonniges, T.F.; Osterhus, E.; Taba, S. History of the medical home concept. Pediatrics 2004, 113 (Suppl. 4), $1473-1478$. [PubMed]

36. Fuentes, M.; Coker, T.R. Social Complexity as a Special Health Care Need in the Medical Home Model. Pediatrics 2018, 142, e20182594. [CrossRef] [PubMed]

37. Nelson, C.S.; Higman, S.M.; Sia, C.; McFarlane, E.; Fuddy, L.; Duggan, A.K. Medical Homes for At-Risk Children: Parental Reports of Clinician-Parent Relationships, Anticipatory Guidance, and Behavior Changes. Pediatrics 2005, 115, 48-56. [CrossRef]

38. Simon, T.D.; Phibbs, S.; Dickinson, L.M.; Kempe, A.; Steiner, J.F.; Davidson, A.J.; Hambidge, S.J. Less Anticipatory Guidance is Associated with More Subsequent Injury Visits among Infants. Ambul. Pediatr. 2006, 6, 318-325. [CrossRef] [PubMed]

39. Dubowitz, H.; Feigelman, S.; Lane, W.; Kim, J. Pediatric Primary Care to Help Prevent Child Maltreatment: The Safe Environment for Every Kid (SEEK) Model. Pediatrics 2009, 123, 858-864. [CrossRef] [PubMed]

40. Dubowitz, H.; Lane, W.G.; Semiatin, J.N.; Magder, L.S. The SEEK Model of Pediatric Primary Care: Can Child Maltreatment Be Prevented in a Low-Risk Population? Acad. Pediatr. 2012, 12, 259-268. [CrossRef]

41. Garner, A.S.; Shonkoff, J.P.; Siegel, B.S.; Dobbins, M.I.; Earls, M.F.; McGuinn, L.; Pascoe, J.; Wood, D.L.; Committee on Psychosocial Aspects of Child and Family Health; Committee on Early Childhood, Adoption, and Dependent Care. Early Childhood Adversity, Toxic Stress, and the Role of the Pediatrician: Translating Developmental Science into Lifelong Health. Pediatrics 2012, 129, e224-e231. [CrossRef] [PubMed]

42. Shonkoff, J.P.; Garner, A.S.; Siegel, B.S.; Dobbins, M.I.; Earls, M.F.; McGuinn, L.; Pascoe, J.; Wood, D.L.; The Committee on Psychosocial Aspects of Child and Family Health; Committee on Early Childhood, Adoption, and Dependent Care. The Lifelong Effects of Early Childhood Adversity and Toxic Stress. Pediatrics 2012, 129, e232-e246. [CrossRef]

43. Campbell, K.A.; Gamarra, E.; Frost, C.J.; Choi, B.; Keenan, H.T. Childhood Adversity and Health after Physical Abuse. Pediatrics 2020, 146, e20200638. [CrossRef]

44. Lanier, P.; Kohl, P.L.; Raghavan, R.; Auslander, W. A Preliminary Examination of Child Well-Being of Physically Abused and Neglected Children Compared to a Normative Pediatric Population. Child Maltreatment 2015, 20, 72-79. [CrossRef]

45. U.S. Department of Health \& Human Services; Administration for Children and Families; Administration on Children; Children's Bureau. Child Maltreatment 2019. 2021. Available online: https:/ /www.acf.hhs.gov/cb/research-data-technology/statisticsresearch/child-maltreatment (accessed on 1 July 2021).

46. Campbell, K.A.; Cook, L.J.; LaFleur, B.J.; Keenan, H.T. Household, family, and child risk factors after an in-vestigation for suspected child maltreatment: A missed opportunity for prevention. Arch. Pediatrics Adolesc. Med. 2010, 164, 943-949. [CrossRef]

47. Campbell, K.A.; Thomas, A.M.; Cook, L.J.; Keenan, H.T. Longitudinal Experiences of Children Remaining at Home after a First-Time Investigation for Suspected Maltreatment. J. Pediatr. 2012, 161, 340-347. [CrossRef]

48. Campbell, K.A.; Olson, L.M.; Keenan, H.T.; Morrow, S.L. What happened next: Interviews with mothers after a finding of child maltreatment in the household. Qual. Health Res. 2017, 27, 155-169. [CrossRef] [PubMed]

49. Flaherty, E.G.; Sege, R.D.; Hurley, B.T.P.; Hurley, T.P. Translating Child Abuse Research into Action. Pediatrics 2008, 122 (Suppl. 1), S1-S5. [CrossRef] [PubMed]

50. Flaherty, E.G.; Sege, R.D.; Hurley, T.P.; Baker, A. Strategies for Saving and Improving Children's Lives: TABLE 1. Pediatrics 2008, 122 (Suppl. 1), S18-S20. [CrossRef]

51. McCarthy, C. Doing the Right Thing: A Primary Care Pediatrician's Perspective on Child Abuse Reporting. Pediatrics 2008, 122 (Suppl. 1), S21-S24. [CrossRef]

52. Goad, J. Understanding Roles and Improving Reporting and Response Relationships across Professional Boundaries. Pediatrics 2008, 122 (Suppl. 1), S6-S9. [CrossRef]

53. Committee on Child Abuse and Neglect. Child Abuse, Confidentiality, and the Health Insurance Portability and Accountability Act. Pediatrics 2010, 125, 197-201. [CrossRef]

54. Block, R.W.; Palusci, V.J. Child Abuse Pediatrics: A new pediatric subspecialty. J. Pediatr. 2006, 148, 711-712. [CrossRef]

55. Giardino, A.P.; Hanson, N.; Leventhal, J.M.; Hill, K.S. Child Abuse Pediatrics: New Specialty, Renewed Mission. Pediatrics 2011, 128, 156-159. [CrossRef] [PubMed]

56. Anderst, J.; Kellogg, N.; Jung, I. Is the diagnosis of physical abuse changed when Child Protective Services consults a Child Abuse Pediatrics subspecialty group as a second opinion? Child Abus. Negl. 2009, 33, 481-489. [CrossRef] [PubMed]

57. Lane, W.G.; Dubowitz, H. Primary care pediatricians' experience, comfort and competence in the evaluation and management of child maltreatment: Do we need child abuse experts? Child Abus. Negl. 2009, 33, 76-83. [CrossRef] [PubMed] 
58. McGuire, L.; Martin, K.D.; Leventhal, J.M. Child Abuse Consultations Initiated by Child Protective Services: The Role of Expert Opinions. Acad. Pediatr. 2011, 11, 467-473. [CrossRef] [PubMed]

59. Zlotnik, S.; Wilson, L.; Scribano, P.; Wood, J.N.; Noonan, K. Mandates for Collaboration: Health Care and Child Welfare Policy and Practice Reforms Create the Platform for Improved Health for Children in Foster Care. Curr. Probl. Pediatr. Adolesc. Health Care 2015, 45, 316-322. [CrossRef]

60. Svedin, L.; Myrup, T.; Jacquez, F. Search of Child Welfare and Child healthcare Collaboration, 1st ed.; Svedin, L., Jacquez, F., Eds.; University of Cincinnati Press: Cincinnati, OH, USA, 2020.

61. Kilo, C.M. Improving care through collaboration. Pediatrics 1999, 103 (Suppl. E1), 384-393.

62. Carbone, P.S.; Norlin, C.; Young, P.C. Improving Early Identification and Ongoing Care of Children with Autism Spectrum Disorder. Pediatrics 2016, 137, e20151850. [CrossRef] [PubMed]

63. Shaw, J.S.; Norlin, C.; Gillespie, R.; Weissman, M.; McGrath, J. The National Improvement Partnership Network: State-Based Partnerships That Improve Primary Care Quality. Acad. Pediatr. 2013, 13, S84-S94. [CrossRef]

64. Young, P.C.; DeBry, S.; Jackson, W.D.; Metos, J.; Joy, E.; Templeman, M.; Norlin, C. Improving the Prevention, Early Recognition, and Treatment of Pediatric Obesity by Primary Care Physicians. Clin. Pediatr. 2010, 49, 964-969. [CrossRef] [PubMed]

65. Young, P.C.; Glade, G.B.; Stoddard, G.J.; Norlin, C. Evaluation of a Learning Collaborative to Improve the Delivery of Preventive Services by Pediatric Practices. Pediatrics 2006, 117, 1469-1476. [CrossRef] [PubMed]

66. Aarons, G.A.; Fettes, D.L.; Hurlburt, M.S.; Palinkas, L.A.; Gunderson, L.; Willging, C.E.; Chaffin, M. Collaboration, Negotiation, and Coalescence for Interagency-Collaborative Teams to Scale-Up Evidence-Based Practice. J. Clin. Child Adolesc. Psychol. 2014, 43, 915-928. [CrossRef] [PubMed]

67. Hanson, R.F.; Schoenwald, S.; Saunders, B.E.; Chapman, J.; Palinkas, L.A.; Moreland, A.D.; Dopp, A. Testing the CommunityBased Learning Collaborative (CBLC) implementation model: A study protocol. Int. J. Ment. Health Syst. 2016, 10, 52. [CrossRef] 